\title{
Crioprotetor para sêmen de carneiro a base de plasma de gema mantém membrana acrossomal intacta após a descongelação
}

\author{
Ram semen cryoprotector based on egg yolk plasma maintain the viability of acrosomal membrane
}

\author{
Ivo Walter dos Santos ${ }^{I}$ Jandui Escarião da Nóbrega Junior ${ }^{I I}$ Matheus Pedrotti de Cesaro \\ Gustavo Freitas Ilha ${ }^{\text {II }}$ Monique Tomazele RovaniI Paulo Bayard Dias Gonçalves ${ }^{\text {II }}$
}

RESUMO

\begin{abstract}
O presente estudo teve como objetivo avaliar a capacidade crioprotetora das lipoproteinas de baixa densidade (LDL) presentes no plasma de gema de ovo, adicionado ao trihidroxiaminometano (TRIS) para congelar sêmen ovino. Trinta e seis ejaculados foram coletados para formar 12 "pool". Cada alíquota de sêmen foi diluída em TRIS-gema de ovo (TRISG) ou TRIS- plasma de gema de ovo (TRISP) antes de congelar o sêmen. Para a obtenção do plasma da gema de ovo, foi utilizado o método de ultracentrifugação. Após o descongelamento, não houve diferença entre os dois extensores em relação aos parâmetros seminais (motilidade, viabilidade, membrana acrossômica e plasma). No entanto, no Teste de Termo Resistência Lenta (TTRL $-4 h / 38^{\circ} \mathrm{C}$ ), o sêmen congelado com TRISP resultou no aumento do número de espermatozoides com acrossoma intacto $(P<0,032)$. Conclui-se que o diluente TRISP é uma alternativa para criopreservação do sêmen de carneiros, pois permite uma melhora da característica seminal em relação ao diluente TRIS gema, mas sem a necessidade do processo de purificação das $L D L$.
\end{abstract}

Palavras-chave: espermatozoide, ovino, lipoproteina de baixa densidade, TRIS.

\section{ABSTRACT}

The present study aimed to evaluate the cryoprotectant low-density lipoprotein ( $L D L)$ present in the plasma of egg yolk added to the extender trihidroxiaminometano (TRIS) for freezing ram semen. Thirty-six ejaculates were collected to form 12 pool. Each aliquot of semen was diluted in TRIS-egg yolk (TRISG) or TRIS-egg yolk plasma (TRISP) before freezing the semen. The plasma of egg yolk was obtained by ultracentrifugation. After thawing, no difference was detected between the two extenders in relation to seminal parameters (motility, viability, plasma membrane and acrosome). However, in the thermal resistance slow test (4h in a water bath at $38^{\circ} \mathrm{C}$ ), the semen frozen with TRISP resulted in higher number of sperm with intact acrosome than those with TRISG $(P<0.032)$. It was concluded that the TRISP extender is an alternative for cryopreservation of ram semen, once it improves the semen characteristics in comparison to TRISG, avoiding the purification process of $L D L$.

Key words: spermatozoa, ovine, low density lipoproteins, TRIS.

\section{INTRODUÇÃO}

As alterações atribuídas ao processo de criopreservação geralmente afetam a estrutura da membrana plasmática, alterando principalmente a disposição da bicamada lipídica da membrana do espermatozoide (LEBOEUF et al., 2000). Com isso, a baixa eficiência do congelamento do sêmen ovino pode ser atribuída ao choque térmico, ao estresse osmótico e ao efeito citotóxico, decorrente da adição e remoção de substâncias crioprotetoras, além da desidratação celular e formação dos cristais de gelo. Dessa forma, a ação conjunta destes fatores pode comprometer a integridade da membrana plasmática e viabilidade espermática após o descongelamento (WATSON, 2000; SALAMON\& MAXWELL, 2000). Portanto, a manutenção da integridade da membrana plasmática é fundamental para manter a viabilidade do espermatozoide no trato reprodutivo da fêmea, até a fertilização (FLESCH \& GADELLA, 2000).

\footnotetext{
IDepartamento de Medicina Veterinária, Universidade Federal do Paraná (UFPR), 85950-000, Palotina, PR, Brasil. E-mail: santosiw@ufpr.br. Autor para correspondência.

ILLaboratório de Biotecnologia e Reprodução Animal, Departamento de Clínica de Grandes Animais, Universidade Federal de Santa Maria (UFSM), Santa Maria, RS, Brasil.
} 
Após o descongelamento, é possível identificar uma grande quantidade de espermatozoides móveis, embora com membrana plasmática lesada. Dessa forma, os espermatozoides têm a motilidade comprometida quando incubados a $37^{\circ} \mathrm{C}$. Portanto, um dos pontos críticos para o sucesso da criopreservação dos espermatozoides de carneiros é a manutenção da integridade da membrana plasmática (VALCÁRCEL et al., 1997).

Uma alternativa viável é o uso do plasma da gema de ovo, composto por $85 \%$ de lipoproteínas de baixa densidade (LDL) e $15 \%$ por levitinas. Essas proteínas são solúveis e podem ser separadas dos grânulos lipídicos através de centrifugação (NILSSON et al., 2006). Em bovinos, foi demonstrado que as LDL presentes na gema de ovo são substâncias importantes para proteção dos espermatozoides durante a criopreservação (MOUSSA et al., 2002; AMIRAT et al., 2004). Entretanto, as LDL competem com os peptídeos catiônicos presentes no plasma seminal, os quais são prejudiciais à membrana espermática, além de formar um complexo contra as proteínas do plasma seminal (PPS) (MANJUNATH et al., 2002; MANJUNATH \& THÉRIEN, 2002).

A purificação das LDL a partir do plasma de gema de ovo tem sido utilizada para criopreservação de sêmen ovino (TONIETO et al., 2010; MOUSTACAS et al., 2011). MOUSSA et al. (2002) propuseram uma técnica utilizando Sulfato de Amônio para o isolamento das LDL, porém esta técnica necessita de cuidados especiais no seu processo. MOUSTACAS et al. (2011) criopreservaram sêmen de carneiro com diluidor TRIS, adicionado de 8, 12, 16 e $20 \%$ de LDL purificada não liofilizada, e obtiveram a concentração de $8 \%, 20 \%$ de espermatozoides com membrana plasmática e acrossomal intactas, avaliadas por sondas fluorescentes. Após a descongelação, TONIETO et al. (2010) obtiveram sêmen com motilidade superior a $40 \%$, integridade de membrana plasmática de $23 \%$ e integridade de acrossoma acima de $38 \%$ usando sêmen de carneiro congelado com TRIS-LDL-glicerol. O objetivo deste estudo foi avaliar a capacidade crioprotetora das LDL não purificadas, presentes no plasma de gema de ovo, adicionado ao TRIS para congelamento de sêmen ovino, buscando assim um diluente para sêmen de carneiro que preserve a integridade da membrana plasmática e possibilite a manutenção da motilidade espermática após o processo de criopreservação.

\section{MATERIAL E MÉTODOS}

O experimento foi realizado na Região Central do Rio Grande do Sul - Brasil, durante os meses de Abril a Julho de 2012. Foram utilizados três Carneiros das raças Ille de France, Texel e Sufolk com idade média de três anos, mantidos em piquetes com pastagens formadas por aveia e azevém e suplementados com concentrado comercial, sal mineral e água à vontade durante a estação reprodutiva. As coletas de sêmen foram realizadas com uso de vagina artificial uma vez por semana, perfazendo 12 coletas por animal, totalizando 36 ejaculados. Após a coleta, cada ejaculado foi avaliado quanto ao volume (medido em tubo graduado), concentração (câmara de Neubauer), movimento em massa, percentual de espermatozoides móveis e vigor, de acordo com SALAMON \& MAXWELL (2000). Foram utilizados apenas ejaculados com volume superior a $0,5 \mathrm{~mL}$, concentração mínima de espermatozoides de $2,5 \times 10^{9}$ células $\mathrm{mL}^{-1}$, motilidade massal e vigor mínimo de 3 (escore 0-5), percentual de espermatozoides móveis superior a $80 \%$ e percentual de patologias espermáticas inferior a $15 \%$. As amostras que não apresentaram os parâmetros citados foram descartadas.

Diluidor I: TRIS Gema (TRISG)- composto de 3,63g de TRIS (Merck - 1.08382 - Germany), $1 \mathrm{~g}$ de glicose (Merck - 1.0024 - Germany), 1,96g de ácido cítrico (Merck - 1.05323 - Germany), 0,06g de penicilina G (Sigma - P 3032 - USA), 0,1g de estreptomicina (Sigma - S 6501 - USA), 5mL de glicerol (Merck 1.04094 - Germany), $15 \mathrm{~mL}$ de gema de ovo e $100 \mathrm{~mL}$ água bidestilada (SALAMON \& MAXWELL, 2000).

Diluidor II: TRIS Plasma de gema de ovo (TRISP) - composto de 3,63g de TRIS (Merck 1.08382 - Germany), $1 \mathrm{~g}$ de glicose (Merck - 1.0024 - Germany), 1,96g de ácido cítrico (Merck - 1.05323 - Germany), 0,06g de penicilina G (Sigma - P 3032 -USA), 0,1g de estreptomicina (Sigma - S 6501 USA), 5mL de glicerol (Merck - 1.04094 - Germany), $15 \mathrm{~mL}$ de plasma de gema de ovo e $100 \mathrm{~mL}$ de água bidestilada (SALAMON \& MAXWELL, 2000).

Para a obtenção do plasma da gema de ovo, foi utilizada ultracentrifugação, conforme metodologia adaptada de MOUSSA et al. (2002). A gema foi diluída em solução salina de baixa força iônica $(\mathrm{NaCl} 0,17 \mathrm{M})$, na proporção de 1:2 e homogeneizada por 30 minutos. A solução foi centrifugada a $12.000 \mathrm{xg} / 45 \mathrm{minutos} / 5^{\circ} \mathrm{C}$. O pellet foi descartado e o sobrenadante foi centrifugado novamente $\left(12.000 \mathrm{xg} / 45 \mathrm{minutos} / 5^{\circ} \mathrm{C}\right)$. Ao final, o sobrenadante resultante é o plasma da gema. 
Após a formação do pool (minimizando o efeito individual), cada ejaculado foi dividido em duas partes iguais, sendo uma parte diluída em TRISG e outra em TRISP a $35^{\circ} \mathrm{C}$ em banho-maria, na concentração de $200 \times 10^{6} \mathrm{sptz} \mathrm{mL}^{-1}$. Após a diluição pelo método One Step, o sêmen foi envasado em palhetas de $0,5 \mathrm{~mL}$ previamente identificadas, na concentração de $100 \times 10^{6} \mathrm{sptz} \mathrm{mL}^{-1}$. As palhetas foram lacradas e mantidas por $5^{\circ} \mathrm{C} / 2 \mathrm{~h}$ para estabilização da temperatura e, em seguida, colocadas a $5 \mathrm{~cm}$ de altura do nitrogênio líquido/15min. Decorrido esse tempo, as palhetas foram mantidas até a descongelação em botijão com nitrogênio líquido $\left(-196^{\circ} \mathrm{C}\right)$.

Após a criopreservação, as palhetas de sêmen foram descongeladas em banho-maria a $37^{\circ} \mathrm{C} / 30$ segundos. Uma amostra do sêmen foi analisada no microscópio de contraste de fase (CF) em aumento de 100x, para observação da motilidade e vigor. O restante das palhetas foi incubada em banhomaria a $38^{\circ} \mathrm{C} / 4 \mathrm{~h}$ para o teste de termo resistência lento (TTRL), objetivando analisar a longevidade e resistência dos espermatozoides para as mesmas características de avaliação.

A avaliação da viabilidade da membrana plasmática e acrossomal foi realizada com sondas fluorescentes em microscopia de epifluorescência. A coloração foi feita através de sondas fluorescentes de iodeto de propídeo, associada ao isotiocianato de fluoresceína conjugado com Pisum Sativum Agglutinin (IP + FITC-PSA), de acordo com a metodologia descrita por CELEGHINI et al. (2010) e SEVERO et al. (2011). Após a descongelação, uma alíquota de $150 \mu \mathrm{L}$ de sêmen foi diluída em meio TALP esperma $\left(25 \times 10^{6} \mathrm{sptz}^{-1}\right)$, colocada em tubo aquecido e, em seguida, adicionado $3 \mu \mathrm{L}$ de IP $\left(0,5 \mathrm{mg} \mathrm{mL}^{-1}\right)$ e $50 \mu \mathrm{L}$ de FITC-PSA $\left(100 \mu \mathrm{g} \mathrm{mL}^{-1}\right)$. As amostras foram incubadas durante 8 minutos em câmara escura a $37^{\circ} \mathrm{C}$. Uma amostra de $8 \mu$ l foi colocada entre lâmina e lamínula e avaliada em microscópio de epifluorescência (Leica, modelo DMI 4000B, Wetzlar, Germany), apresentando um conjunto: L5-BP (480/40, RKP 505, BP 527/30; N2.1-BP (515-560 RKP 580 LP 590). Foram contados 200 espermatozoides por lâmina sob objetiva de imersão e classificados com base na cor da fluorescência, emitida a partir de cada sonda.

A normalidade dos dados foi verificada por meio do teste de Shapiro-Wilk e os dados em porcentagem transformados em arco-seno para melhorar a sua distribuição. Para os dados de vigor, utilizou-se a análise não paramétrica de KruskalWallis. A média e o desvio padrão foram usados para apresentação dos parâmetros do sêmen fresco. Para a avaliação do sêmen congelado, foi utilizada a análise de variância (ANOVA), avaliando os parâmetros entre os tratamentos TRISG e TRISP por ocasião da descongelação e após o TTRL, considerando nível de significância de $\mathrm{P}<0,05$ (SAS).

\section{RESULTADOS E DISCUSSÃO}

Os parâmetros do sêmen fresco dos carneiros utilizados neste trabalho estão descritos na tabela 1. Para minimizar o efeito individual e racial, foram agrupadas as amostras do sêmen de cada animal para obtenção do pool. Diante disso, os resultados demonstraram que os parâmetros (motilidade, vigor, membrana plasmática intacta, acrossoma intacto, membrana e acrossoma intactos) do sêmen dos carneiros avaliados imediatamente após a descongelação não diferiram significativamente para o TRISG e TRISP (Tabela 2). Na avaliação do sêmen descongelado após TTRL, não foi observada diferença $(\mathrm{P}>0,05)$ entre os tratamentos TRISG e TRISP em relação à motilidade, vigor e membrana plasmática (Figura 1). Entretanto, a variável acrossoma intacto (ACI) foi significativa, sendo o diluidor TRISP superior $(\mathrm{P}<0,032)$ em comparação ao diluidor TRISG (Figura 1).

No presente estudo, utilizou-se o diluidor TRIS adicionado de plasma de gema, que, segundo NILSSON et al. (2006), possui $85 \%$ de LDL, sendo esta a principal substância crioprotetora de membrana espermática. Apenas a adição de plasma de gema não mostrou melhora das funções do espermatozoide por ocasião do descongelamento do sêmen, quando comparado ao desempenho do diluidor já conhecido, TRISG (Tabela 2). Este fato pode ser explicado pelo uso do plasma da gema e não de LDL purificadas, concordando com os relatos de MOUSSA et al. (2002); AMIRAT et al. (2005); BERGERON \& MANJUNATH (2006), os quais afirmam que as LDL

Tabela 1 - Parâmetros avaliados no sêmen fresco dos carneiros para formação dos "pool", colhidos com vagina artificial, média e desvio padrão $( \pm)$

\begin{tabular}{lll}
\hline Parâmetros & Média & $\mathbf{( \pm )}$ \\
\hline Turbilhão (0-5) & 3,8 & 0,55 \\
Motilidade (\%) & 86,7 & 3,3 \\
Vigor (0-5) & 3,9 & 0,4 \\
Concentração (bilhões/mL) & 2,5 & 1,9 \\
Membrana plasmática intacta (\%) & 85,2 & 2,0 \\
Acrossoma intacto (\%) & 87,5 & 2,6 \\
Membrana e acrossoma intactos (\%) & 84,8 & 1,7 \\
\hline
\end{tabular}


Tabela 2 - Parâmetros do sêmen dos carneiros diluídos com TRIS-gema de ovo (TRISG) ou TRIS- plasma de gema de ovo (TRISP). Média e desvio padrão $( \pm)$ após descongelação. Letras diferentes demonstram diferenças entre os tratamentos $(\mathrm{P}<0,05)$.

\begin{tabular}{lcc}
\hline & & \\
Parâmetros & TRISG & TRISP \\
\hline Motilidade (\%) & $57,1( \pm 1,9)$ & $57,9( \pm 1,6)$ \\
Vigor (0-5) & $3,6( \pm 0,1)$ & $3,7( \pm 0,1)$ \\
Membrana plasmática intacta (\%) & $49,4( \pm 1,9)$ & $50,6( \pm 1,7)$ \\
Acrossoma intacto (\%) & $51,7( \pm 1,9)$ & $52,4( \pm 2,0)$ \\
Membrana e acrossoma intactos (\%) & $49,2( \pm 1,9)$ & $50,4( \pm 1,8)$ \\
\hline
\end{tabular}

competem com os peptídeos catiônicos presentes no plasma seminal, além de formar um complexo contra as proteínas do plasma seminal (PPS). Por outro lado, MOUSTACAS et al. (2011) verificaram que o uso das LDL purificadas e sem liofilização resultou em motilidade espermática semelhante ao diluente TRIS adicionado de gema de ovo. O presente estudo utilizou plasma de gema de ovo ( $85 \%$ de LDL), o qual é obtido em processo rápido, simples e que apresentou resultados condizentes aos obtidos com diluentes adicionados de LDL purificado.

Após a descongelação do sêmen, foi encontrado $49,25 \%( \pm 1,93)$ e $50,41 \%( \pm 1,76)$ de espermatozoides com membrana e acrossoma intactos para os diluidores TRISG e TRISP, respectivamente. Estes resultados foram superiores aos achados de
TONIETO et al. (2010) e MOUSTACAS et al. (2011), os quais encontraram valores abaixo de $22 \%$ de espermatozoides com membrana plasmática e acrossomal intactas, quando congelados com TRIS adicionado de $8 \%$ de LDL. Esta discrepância pode ser decorrente da metodologia de congelamento, concentração dos constituintes do diluidor ou da purificação das LDL.

Após o TTRL, foi constatada a manutenção dos espermatozoides com membrana plasmática intacta e acrossoma intacto $(16 \% \pm 1,18)$, empregando o TRISP como diluidor em relação ao TRISG $(13,5 \% \pm 1,1)$. Os resultados obtidos nesta pesquisa possibilitaram melhorias dos parâmetros seminais, utilizando o TRISP como diluidor (Figura 1) sem a necessidade do processo de purificação das LDL.

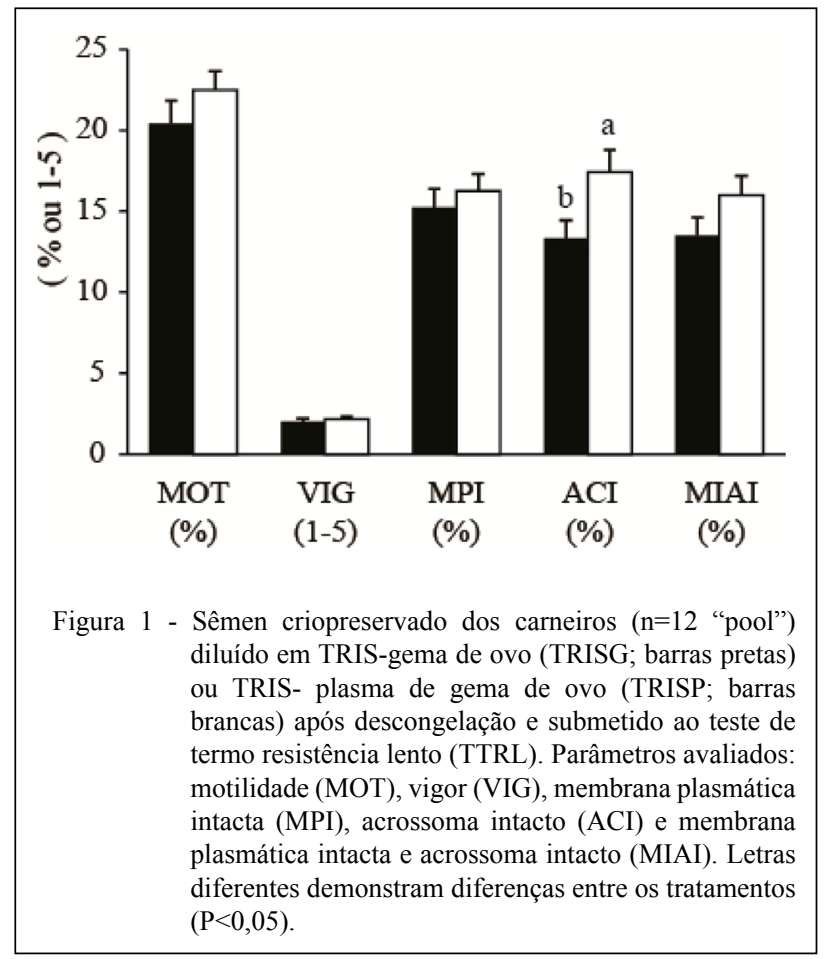

Ciência Rural, v.45, n.6, jun, 2015. 
Esses resultados são reforçados pelos relatos de VALCÁRCEL et al. (1997), os quais afirmam que espermatozoides com membrana lesada perdem a motilidade rapidamente, quando incubada a $37^{\circ} \mathrm{C}$. Na avaliação da integridade do acrossoma (Figura 1), o diluidor TRISP foi significativo $(17,41 \% \pm 1,39)$ quando comparado com o TRISG $(13,33 \% \pm 1,1 ; \quad \mathrm{P}<0,032)$, igualmente aos resultados descritos por VALCÁRCEL et al. (1997), os quais referem-se a que a membrana plasmática apresenta maior fragilidade em relação à membrana acrossomal externa.

Segundo BERGERON et al. (2004), quando o sêmen é diluído logo após a coleta, em diluente incluído de gema de ovo, as LDL sequestram as proteínas presentes no plasma seminal (PPS), impedindo que estas fiquem disponíveis para atuarem na membrana, e reduzindo assim a intensidade das alterações desta. O presente estudo foi realizado com amostras de sêmen provenientes de pool de três ejaculados e o tempo para a confecção do "pool" até a diluição do sêmen pode ter sofrido influências das PPS sobre a membrana plasmática do espermatozoide, influenciando no resultado após TTRL, com resultados que são semelhantes aos relatos descritos por MANJUNATH et al. (2002) e MANJUNATH \& THÉRIEN (2002).

\section{CONCLUSÃO}

A utilização de diluente rico em LDL não purificado, obtido pela ultracentrifugação do plasma da gema de ovo, adicionado ao TRIS, é uma alternativa para criopreservação do sêmen de carneiros, pois, permite uma melhora da característica seminal em relação ao diluente TRIS gema, mas sem a necessidade do processo de purificação das LDL.

\section{AGRADECIMENTOS}

Ao Conselho Nacional de Desenvolvimento Científico e Tecnológico (CNPq) e Fundação de Amparo à Pesquisa do Estado do Rio Grande do Sul (FAPERGS) pelo financiamento e ao Setor de Ovinocultura da Universidade Federal de Santa Maria (UFSM).

\section{REFERÊNCIAS}

AMIRAT, L. et al. Bull semen in vitro fertility after cryopreservation using egg yolk LDL: a comparison with Optidyl ${ }^{\circledR}$, a commercial egg yolk extender. Theriogenology, v.61, p.895-907. 2004. Disponível em: <http:/www.sciencedirect.com/science/article/pii/ S0093691X03002590>. Acesso em: 20 mar. 2013. doi:10.1016/ S0093-691X(03)00259-0.

AMIRAT, L. et al. Modifications of bull spermatozoa induced by three extenders: Biociphos ${ }^{\circledR}$, low density lipoprotein and
Trilady $l^{\circledR}$, before, during and after freezing and thawing. Research Reproduction, v.4, p.535-543, 2005. Disponível em: <http:// www.reproduction-online.org/content/129/4/535.long>. Acesso em: 20 mar. 2013. doi:10.1530/rep.1.00011.

BERGERON, A. et al. Low-density lipoprotein fraction from hen's egg yolk decreases the binding of the major protein of bovine seminal plasma to sperm and prevents lipid efflux from the sperm membrane. Biology of Reproduction, v.70, p.708-717, 2004. Disponível em: <http://www.biolreprod.org/ content/70/3/708.long >. Acesso em: 20 mar. 2013. doi:10.1095/ biolreprod.103.022996.

BERGERON, A.; MANJUNATH, P. New Insights towards understanding the mechanisms of sperm protection by egg yolk and milk. Molecular Reproduction and Development, v.73, p.1338-1344, 2006. Disponível em: <http://onlinelibrary.wiley. com/doi/10.1002/mrd.20565/pdf>. Acesso em: 12 fev. 2013. doi: $10.1002 / \mathrm{mrd} .20565$

CELEGHINI E.C.C. et al. Simultaneous assessment of plasmatic, acrossomal, and mitochondrial membranes in ram sperm by fluorescent probes. Arquivo Brasileiro de Medicina Veterinária e Zootecnia, v.62, p.536-543, 2010. Disponível em: $<$ http://www. scielo.br/pdf/abmvz/v62n3/06.pdf $>$. Acesso em: 12 fev. 2013. doi:10.1590/S0102-09352010000300006.

FLESCH, F.M.; GADELLA, B.M. Dynamics of mammalian sperm membrane in the process of fertilization. Biochemical and Biophysical Acta, v.1469, p.197-235, 2000. Disponível em: <http:// www.sciencedirect.com/science/article/pii/S0304415700000186>. Acesso em: 20 mar. 2013. doi:10.1016/S0304-4157(00)00018-6.

LEBOEUF, B. et al. Production and storage of goat semen for artificial insemination. Animal Reproduction Science, v.62, p.113-41, 2000. Disponível em: <http://www.sciencedirect.com/ science/article/pii/S0378432000001561>. Acesso em: $12 \mathrm{fev}$. 2013. doi:10.1016/S0378-4320(00)00156-1.

MANJUNATH, P. et al. Major proteins of bovine seminal plasma bind to the low-density lipoprotein fraction of hen's egg yolk. Biology of Reproduction, v.67, p.1250-1258, 2002. Disponível em: <http://www.biolreprod.org/content/67/4/1250.\%20long >. Acesso em: 12 fev. 2013. doi:10.1095/biolreprod67.4.1250.

MANJUNATH, P.; THÉRIEN, I. Role of seminal plasma phospholipid-binding proteins in sperm membrane lipid modification that occurs during capacitation. Journal of Reproductive Immunology, v.53, p.109-119, 2002. Disponível em: <http://www.sciencedirect.com/science/ article/pii/S0165037801000985>. Acesso em: 20 mar. 2013. doi:10.1016/S0165-0378(01)00098-5.

MOUSTACAS, V.S. et al. Natural, but not lyophilized, low density lipoproteins were an acceptable alternative to egg yolk for cryopreservation of ram semen. Theriogenology, v.75, p.300-307, 2011. Disponível em: <http://www.sciencedirect.com/science/ article/pii/S0093691X10004589>. Acesso em: 20 mar. 2013. doi:10.1016/j.theriogenology.2010.08.016.

MOUSSA, M. et al. Low density lipoproteins extracted from hen egg yolk by an easy method: cryoprotective effect on frozenthawed bull semen. Theriogenology, v.57, p.1695-1706, 2002. Disponível em: <http://www.sciencedirect.com/science/article/pii/ S0093691X02006829>. Acesso em: 20 mar. 2013. doi:10.1016/ S0093-691X(02)00682-9. 
NILSSON, L. et al. Competitive adsorption of water soluble plasma proteins form egg yolk at the water/oil interface. Journal of Agricultural and Food Chemistry, v.54, p.6881-6887, 2006. Disponível em: <http://pubs.acs.org/doi/pdf/10.1021/jf0607381>. Acesso em: 12 fev. 2013. doi:10.1021/jf0607381.

SALAMON, S.; MAXWELL, W.M.C. Storage of ram semen. Animal Reproduction Science, v.62, p.77-111, 2000. Disponível em: <http://www.sciencedirect.com/science/ article/pii/S037843200000155X >. Acesso em: 12 fev. 2013. doi:10.1016/0378-4320(94)01327-I.

SEVERO, C.K. et al. Cysteine addition on short-term cooled boar semen preservation and its relationship with swine field fertility. Pesquisa Veterinária Brasileira, v.31 supl.1, p.2532, 2011. Disponível em: <http://www.scielo.br/pdf/pvb/v31s1/ v31s1a05.pdf $>$. Acesso em: 20 mar. 2013. doi:10.1590/S0100736X2011001300005.
TONIETO, R.A. et al. Cryoprotectant effect of trehalose and low-density lipoprotein in extenders for frozen ram semen. Small Ruminant Research. v.93, p.206-209, 2010. Disponível em: $<$ http:// www.sciencedirect.com/science/article/pii/S0921448810001537>. Acesso em: 20 mar. 2013. doi:10.1016/j.smallrumres.2010.05.003.

VALCÁRCEL, A. et al. Assessment of the acrosomal status of membrane-intact ram spermatozoa after freezing and thawing, by simultaneous lectin/Hoechst 33258 staining. Animal Reproduction Science. v.45, p.299-309, 1997. Disponível em: <http://www. sciencedirect.com/science/article/pii/S0378432096015862>. Acesso em: 20 mar. 2013. doi: 10.1016/S0378-4320(96)01586-2.

WATSON, P.F. The causes of reduced fertility with cryopreserved semen. Animal Reproduction Science, v.61, p.481-492. 2000. Disponível em: <http://www.sciencedirect.com/science/article/pii/ S0378432000000993>. Acesso em: 20 mar. 2013. doi: 10.1016/ S0378-4320(00)00099-3. 